\section{Evaluation of Vetiver Grass Root Growth, Oil Distribution, and Repellency Against Formosan Subterranean Termites}

\author{
Karen E. Nix and Gregg Henderson ${ }^{1}$ \\ Department of Entomology, Louisiana State University Agricultural Center, \\ 402 Life Sciences Building, Baton Rouge, LA, 70803
}

\author{
Betty C.R. Zhu and Roger A. Laine \\ Department of Biological Sciences, Louisiana State University, Baton Rouge, \\ $L A, 70803$
}

Additional index words. Vetiveria zizanioides, subterranean termite, Isoptera, vetiver oil

\begin{abstract}
The growth rate of vetiver grass [Vetiveria zizanioides (L.) Nash (Graminales: Poaceae)], roots, and oil distribution were evaluated in an 8-month field study. The amount of vetiver oil present in the root system increased with each sampling date. In December, the final sampling period, mean root weight increased $520 \%$ from the previous sampling period (October). At the end of the study, root growth measured over $2 \mathrm{~m}$ long and $25 \mathrm{~cm}$ wide and weighed $0.48 \mathrm{~kg}$ (dry weight). In addition, a laboratory study was conducted to determine if the roots of vetiver grass when used as mulch, are effective against Formosan subterranean termites, Coptotermes formosanus Shiraki (Isoptera: Rhinotermitidae). In past studies, chemical components in the roots of this grass were shown to be effective repellents and toxicants to Formosan subterranean termites. In the present study, the 25\% vetiver root mulch treatment proved to decrease tunneling activity and wood consumption and increase termite mortality. These results provide preliminary evidence that vetiver roots may have use as an additive to garden mulches against termites.
\end{abstract}

Vetiver grass, Vetiveria zizanioides (L.) Nash (Graminales: Poaceae), is native to India and possesses an extensive root system beneficial in soil and water conservation where erosion is problematic (Chomchalow, 2001; National Research Council, 1993). The fast growing root system of this plant contains essential oils, natural compounds found in many different plants (Zhu et al., 2001b). Presently, vetiver grass is grown in-ground and because of the extensive root growth, it is extremely difficult to harvest efficiently.

Plants produce many natural compounds that are repellent or act to alter feeding behavior, growth, and development of insects (Duke, 1990). Chemical components of vetiver root are also very important because they possess fungicidal, herbicidal, and insecticidal prop-

Received for publication 12 Sept. 2005. Accepted for publication 18 Nov. 2005. This project was approved for publication by the Director of the Louisiana Agricultural Experiment Station as manuscript number 05-26-0460. This paper is a portion of a thesis submitted by Karen E. Nix in fulfilling a Master of Science degree. We thank Lixin Mao, Abner Hammond, and Seth Johnson for review of this manuscript, Douglas Hurst for his assistance in the field aspect of this experiment, and Huxin Fei, Lixin Mao, and Brian Marx for their help in the data analysis. Huxin Fei is also thanked for collecting termites. Thanks is also extended to Don and Judy Heumann for the vetiver grass plants used and also providing input on designing the method of growing plants.

${ }^{1}$ To whom correspondence should be addressed; e-mail grhenderson@agcenter.lsu.edu. erties. For example, vetiver oil and one of its minor constituents, nootkatone, have been shown to inhibit germination and seed expansion in a variety of economically important weed species (Mao et al., 2004) and possess repellent properties useful against ants, cockroaches, bedbugs, head lice, flies, and moths (Henderson et al., 2005a; National Research Council, 1993). Vetiver oil and some of its constituents are also repellent and toxic to termites (Henderson et al., 2005b; Ibrahim et al., 2004; Zhu et al., 2001a, 2001b).

Termites are ecologically important insects that aid in the breakdown of cellulose material and recycling of nutrients. For homeowners, this important role in nature is overshadowed when termites invade economically important wooden structures such as homes, buildings, and utility poles. In the United States, the most economically important termite is the Formosan subterranean termite, Coptotermes formosanus Shiraki (Isoptera: Rhinotermitidae) (Gold et al., 1999).

Presently, control of subterranean termites depends mainly on the incorporation of synthetic chemical treatments with a long persistence into the soil. There has been an increased public awareness of pesticide use in the urban landscape and an increased desire to reduce their use and implement more environmentally safe control strategies (Forschler and Jenkins, 2000). There is an increasing interest in using natural products in pest control because of their low mammalian toxicity and environmental safety (Duke, 1990). Of interest to homeowners in Louisiana is to use vetiver grass plants or roots from the plant incorporated into mulch for use around the perimeter of a structure as a repellent to termites.

While using vetiver grass roots as mulch against termites as an alternative to insecticides has been a topic of great interest (Chomchalow, 2003), research in this area is lacking. Roots of vetiver plants have been used in many areas of the world as a repellent to a variety of insects (Chomchalow, 2003; National Research Council, 1993). While most of this evidence is anecdotal, it is still useful. Over a century ago, Louisiana strawberry farmers reported that when vetiver grass roots were used as mulch on their crops, the attack of pest insects to this fruit crop were reduced to zero (Chomchalow, 2003; Greenfield, 2002). Dried vetiver grass roots have been used since the early 1900's as sachets to protect stored clothing from mold, mildew, moths, and other insect pests (Greenfield, 2002).

The first objective was to evaluate the root growth of vetiver grass and to determine the relative amount of vetiver oil present in the roots obtained on different sampling dates. The second objective of this study was to determine if the field grown vetiver grass roots, when used as mulch, act as a repellent and/or toxicant to termites in a laboratory setting.

\section{Materials and Methods}

\section{Evaluation of vetiver grass root growth}

Material preparation. Four vetiver grass plants (about 3 years old) were obtained from Donald O. Heumann Greenhouse and Laboratory (Poydras, La.) to be grown above ground using a modified method from previous work (http://www.vetiver.com/ VNN_Root $\% 20$ system.pdf). Five sections of polyvinyl chloride (PVC) sewer pipe standing $2.44 \mathrm{~m}$ tall and $25.40 \mathrm{~cm}$ in diameter (Pipelife Jet Stream Inc., Siloam Springs, Ark.) were used to hold the sand in which the vetiver grass was planted.A3.18-cm-diameter opening was drilled $0.61 \mathrm{~m}$ from the top of the PVC

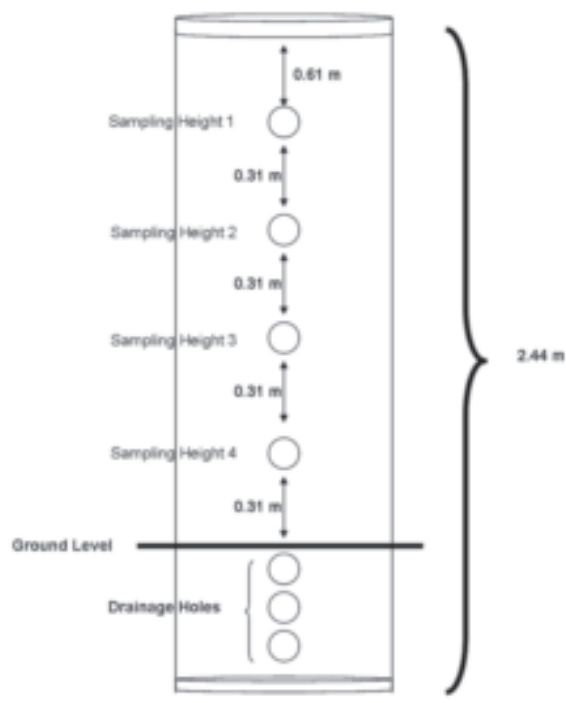

Fig. 1. Diagram of PVC pipe used noting sampling heights, drainage holes, and distances between each of the sampling heights. Note: diagram is not drawn to scale. 
pipe with three additional openings drilled in a straight line every $0.31 \mathrm{~m}$ thereafter (Fig. 1). These openings were used to obtain sand samples. Three to five additional openings were drilled in a straight line $0.46 \mathrm{~m}$ directly below the last sample opening drilled, for water drainage purposes. This drilling procedure was repeated at $90^{\circ}, 180^{\circ}$, and $270^{\circ}$ from the initial line of openings.

Site preparation. Five holes were dug in the ground in a straight line $2.29 \mathrm{~m}$ apart, each at a width of $0.30 \mathrm{~m}$ and a depth of $0.61 \mathrm{~m}$, in St. Gabriel, La. One PVC pipe was placed inside each hole, with the drilled drainage holes going in the ground (Fig. 1). To stabilize each PVC pipe and to aid in water drainage, about 0.014 $\mathrm{m}^{3}$ of gray stone marble (Green Leaf Products, Haines City, Fla.) was placed in the hole around the outside of the PVC pipe. Each PVC pipe was filled with fill sand (AJL Enterprises, St. Gabriel, La.) until level with the top. Each sample opening was covered with duct tape to keep sand from falling out and consecutively numbered 1 to 4 , beginning with the sample opening closest to the top of the PVC pipe, to indicate sampling heights (Fig. 1).

On 16 Apr. 2004, 7 d after setting up the PVC pipes, four were randomly chosen and vetiver grass was planted at an approximate depth of $0.5 \mathrm{~m}$, leaving a $2.54-\mathrm{cm}$ space at the top of each PVC pipe to prevent overflow when watering. One tablespoon of Miracle-Gro all purpose plant food (Scotts Miracle-Gro Co., Marysville, Ohio) was added to each setup at the beginning of the study and again at about 5 months after the vetiver grass was planted. All setups were watered daily with about 3.8 to $7.6 \mathrm{~L}$ of water.

Sand sampling. To analyze roots for the presence of vetiver oil, every 2 months for 8 months, sand samples were obtained using a Bayco chrome plated heavy duty soil probe $(54.34 \times 2.22 \mathrm{~cm}$, Lawrence, Kan.). The duct tape covering was removed and samples were taken from each setup through holes at all 4 sampling heights at the $270^{\circ}$ openings. This directional aspect was randomly selected. The soil probe was inserted through the entire width of the PVC pipe, turned slightly, and then removed. About $25.4 \times 2.06 \mathrm{~cm}$ of sand was extracted and placed in autoclaved $250 \mathrm{ml}$ I-Chem jars $(7.3 \times 8.6 \mathrm{~cm}$; Fisher Scientific, Pittsburg, Pa.). The soil probe was rinsed with $100 \%$ ethyl alcohol after taking each sample. Only one sample, taken from sampling height 1 , was obtained from the control setup for each of the sampling dates. Duct tape was replaced after samples were obtained.

Sample Preparation. Samples were dried for 48 hours in individual polystyrene weighing dishes $(140 \times 140 \times 25 \mathrm{~mm}$; FisherBrand, Fisher Scientific) under a fume hood. Dried samples were returned to their respective I-Chem jar and $100 \mathrm{ml}$ of $100 \%$ ethyl alcohol was added. Each sample was stirred vigorously for $2 \mathrm{~min}$ and filtered into individual, autoclaved 100 $\mathrm{mL}$ Pyrex laboratory bottles (Fisher Scientific) using qualitative filter paper $(18.5 \mathrm{~cm}$, Grade 413; VWR Scientific Products, West Chester, $\mathrm{Pa}$.). Once all liquid was filtered, roots on the filter paper were removed and placed back in the original I-Chem jar. Filtered liquid samples were placed inside a refrigerator. I-Chem jars containing remaining sand and roots were allowed to dry uncovered under a fume hood for $48 \mathrm{~h}$ at which point all vetiver roots were removed from the sand, weighed and recorded.

Ethyl alcohol evaporation. Filtered liquid samples were concentrated in a $50{ }^{\circ} \mathrm{C}$ water bath with a rotary evaporation system (Brinkmann/Büchi Rotovapor RE120; Fisher Scientific). Once the ethyl alcohol was completely evaporated, about 1 to $3 \mathrm{~mL}$ of $100 \%$ ethyl alcohol was added and transferred to a $15 \times 45-\mathrm{mm}$ glass vial (Fisher Scientific). The samples were then dried under nitrogen gas and stored in a freezer set at about $0{ }^{\circ} \mathrm{C}$.

Thin-layer chromatography (TLC). One hundred microliters of $100 \%$ ethyl alcohol were added to each vial and placed on a Vortex Genie 2 shaker (FisherBrand, Fisher Scientific, Pittsburg, Pennsylvania) for 10 seconds. Using a $5 \mu \mathrm{L}$ microcapillary pipet (Kimble Glassware, Vineland, N.J.), $1 \mu \mathrm{L}$ was removed from each sample and spotted on a $10 \times 20$ $\mathrm{cm}$ silica gel TLC plate (Uniplate, Analtech Inc., Newark, Del.). All samples from their respective sampling dates were placed on 1 TLC plate. For comparison purposes, $1 \mu \mathrm{L}$ of vetiver oil (Haitian vetiver oil; The Good Scents Company, Oak Creek, Wis.) was spotted as a standard.

TLC plates were placed inside a glass chamber containing a shallow pool of chloroform so that only the bottoms of the plates were in the liquid. The chamber was covered with a stainless steel lid and left undisturbed until the chloroform was approximately $1 \mathrm{~cm}$ from the top of the TLC plate. Once removed from the developing chamber the TLC plates were allowed to dry under a fume hood for 5 minutes, sprayed lightly with $50 \%$ sulfuric acid, and placed inside an oven at $120^{\circ} \mathrm{C}$ for 10 minutes. TLC plates were scanned with an Epson 2400 photo scanner (Epson Photo 2400; Epson America, Long Beach, Calif.) to fix the images.

Evaluation of vetiver oil quantity. Samples taken at each sampling date were visually evaluated based on the darkness of the spot on the TLC plate using the following scale: 4, very dark; 3, moderate darkness; 2, light; and 1 , very light to no spot present. Darker samples indicated that a larger concentration of vetiver oil was present.

Observation of total root growth. The study was terminated 8 months after planting the vetiver grass and one PVC pipe containing a vetiver grass plant was dismantled to observe root growth. The roots were washed using a water hose to remove sand and debris and were allowed to dry under a fume hood. Once dry, the total root length and weight was recorded.

Statistical analysis. An ANOVA for repeated measures (PROC MIXED, SAS Institute 1989), followed by a least square means post-hoc test was used to compare root weights at each sample height and for each sampling date. Although root weights were transformed to square root for data analysis, untransformed means are reported. An ANOVA for repeated measures (PROC MIXED, SAS Institute 1989) was also performed for each sampling date to determine the relationship between 1) sampling height and root weight, 2) root weight and vetiver oil quantity, and 3) sampling height and vetiver oil quantity.

\section{Vetiver grass root as mulch against termites}

Vetiver root mulch preparation. One of the four vetiver grass plants planted on $16 \mathrm{Apr}$. 2004, as described above, was harvested on 7 June 2005. The roots were rinsed thoroughly with water to remove sand and debris and dried under a fume hood for $5 \mathrm{~d}$. Dried roots were cut with scissors into small pieces (about $1.0 \mathrm{~cm}$ ) and stored in covered plastic containers $(18.89 \times$ $13.81 \times 9.53 \mathrm{~cm}^{3}$; Pioneer Packaging Co., North Dixon, Ky.) under a fume hood for $2 \mathrm{~d}$.

Experimental containers. Three-compartment plastic containers $\left(18 \times 8 \times 4 \mathrm{~cm}^{3}, 5.6 \times\right.$ $8 \times 4 \mathrm{~cm}^{3}$ each chamber; Pioneer Packaging Co.) with small openings $\left(3.5 \times 0.3 \mathrm{~cm}^{2}\right)$ at the bottom of the two inner walls connecting the chambers were used for this experiment. The three chambers were labeled as the nest chamber; where termites were added, treatment chamber (middle chamber), and the food chamber. Untreated balsa wood, Ochroma lagopus Swartz $\left(5.1 \times 1.4 \times 0.1 \mathrm{~cm}^{3}\right)$, was dried under a fume hood for $24 \mathrm{~h}$, weighed, and placed inside the food chamber of all containers. Forty grams of autoclaved fine commercial grade construction sand (Louisiana Cement Products, Greenwell Springs, La.) was moistened with 5 $\mathrm{ml}$ of deionized water. Vetiver root mulch was mixed with the sand in the treatment chamber of each container. Four treatments were tested: control (no vetiver root mulch), $5 \%, 10 \%$, and $25 \%$ vetiver root mulch to sand (wt:wt). Vetiver root mulch for $5 \%, 10 \%$, and $25 \%$ treatments were moistened with 2,4 , and $10 \mathrm{~mL}$ of deionized water, respectively. Ninety worker and ten soldier Formosan subterranean termites from a colony collected in New Orleans, La., on 14 May 2005, were introduced into the nest chambers. To reach the food source, termites had to tunnel through the treatment chamber. Five replicates were performed for each treatment. Each container was covered and placed in a dark incubator at $28{ }^{\circ} \mathrm{C}$ for $16 \mathrm{~d}$.

Tunneling response, consumption, and mortality. On days 4, 8, 12, and 16 the bottom of each container was scanned (Epson Photo 2400; Epson America) to fix the image of the tunnels. Images were printed to actual size to measure total tunnel length. Also, at this time, $5 \mathrm{~mL}$ of deionized water was added to the sand in all of the treatment chambers to maintain high moisture. On day 16 , all containers were dismantled, the number of live termites was counted to determine mortality, and wood slices were cleaned, dried under a fume hood for 24 $\mathrm{h}$, and weighed to determine consumption. Percent mortality was calculated using the formula: ((100-number of live termites $) / 100)$ $\times 100$. Percent consumption of wood slices was calculated using the formula: ((Initial wood weight - final wood weight $) / 100) \times 100$.

Statistical analysis. The length of tunneling for each observation date, percent consumption 
Table 1. Mean weight \pm SD (in g) of vetiver grass roots from all sampling heights for each sampling date.

\begin{tabular}{lc}
\hline Sampling date & Root wt \\
\hline June & $0.07 \pm 0.04 \mathrm{a}^{\mathrm{z}}$ \\
August & $0.07 \pm 0.04 \mathrm{a}$ \\
October & $0.14 \pm 0.07 \mathrm{~b}$ \\
December & $0.86 \pm 0.05 \mathrm{c}$ \\
\hline
\end{tabular}

${ }^{\mathrm{z}}$ Means followed by the same letter are not significantly different at 0.05 level as determined by least square means test.

Table 2. Mean weight \pm SD (g) of vetiver grass roots throughout the study for each sampling height.

\begin{tabular}{lc}
\hline Sampling ht & Root wt \\
\hline 1 & $0.28 \pm 0.35 \mathrm{a}^{2}$ \\
2 & $0.29 \pm 0.35 \mathrm{a}$ \\
3 & $0.27 \pm 0.36 \mathrm{a}$ \\
4 & $0.28 \pm 0.35 \mathrm{a}$ \\
\hline
\end{tabular}

${ }^{\mathrm{z}}$ Means followed by the same letter are not significantly different at 0.05 level as determined by least square means test.

of the wood samples, and percent mortality were analyzed using an analysis of variance (ANOVA) procedure (PROC GLM, SAS Institute 1989). The means were separated using Tukey's studentized range (HSD) test. Although tunnel length for day 4 and percent consumption +1 were transformed to $\log$ to promote normality for data analysis, untransformed means are reported.

\section{Results}

Evaluation of vetiver grass root growth. Mean root weights from the fourth sampling date (December) were significantly higher than all other sampling dates with a mean weight of $0.862 \mathrm{~g}(\mathrm{~F}=391.22 ; \mathrm{df}=3,9 ; P<0.0001)$ (Table 1), indicating a $520 \%$ increase from the previous sampling period. There was no difference in mean root weight with respect to sampling heights $(\mathrm{F}=0.93 ; \mathrm{df}=3,9 ; P=$ 0.47) (Table 2).

Comparison of all TLC plates with the vetiver oil standard TLC plate indicated the presence of oil in the vetiver root samples. The amount of vetiver oil present in the roots increased with each sampling date, as evidenced by darker spots on the TLC plate (Fig. 2).

There was a significant decrease in the amount of vetiver oil present in the roots with distance for the second sampling date (August: $P<0.0001$ ). Mean root weight decreased significantly with distance at the second sampling date (August: $P<0.0001$ ). As mean root weight increased the amount of vetiver oil increased for the second and third sampling date (August: $P=0.0007$, October: $P<0.0001$, respectively).

Fig. 2. TLC plate for (a) first sampling date (June), (b) second sampling date (August),(c) third sampling date (October), and (d) fourth sampling date (December). The first line for each plant are the samples taken from sampling height 1 , the second line for each plant are those taken from sampling height 2 , continuing to the last (fourth) sample for each plant being the sample taken at the lowest sampling height (sampling height 4).

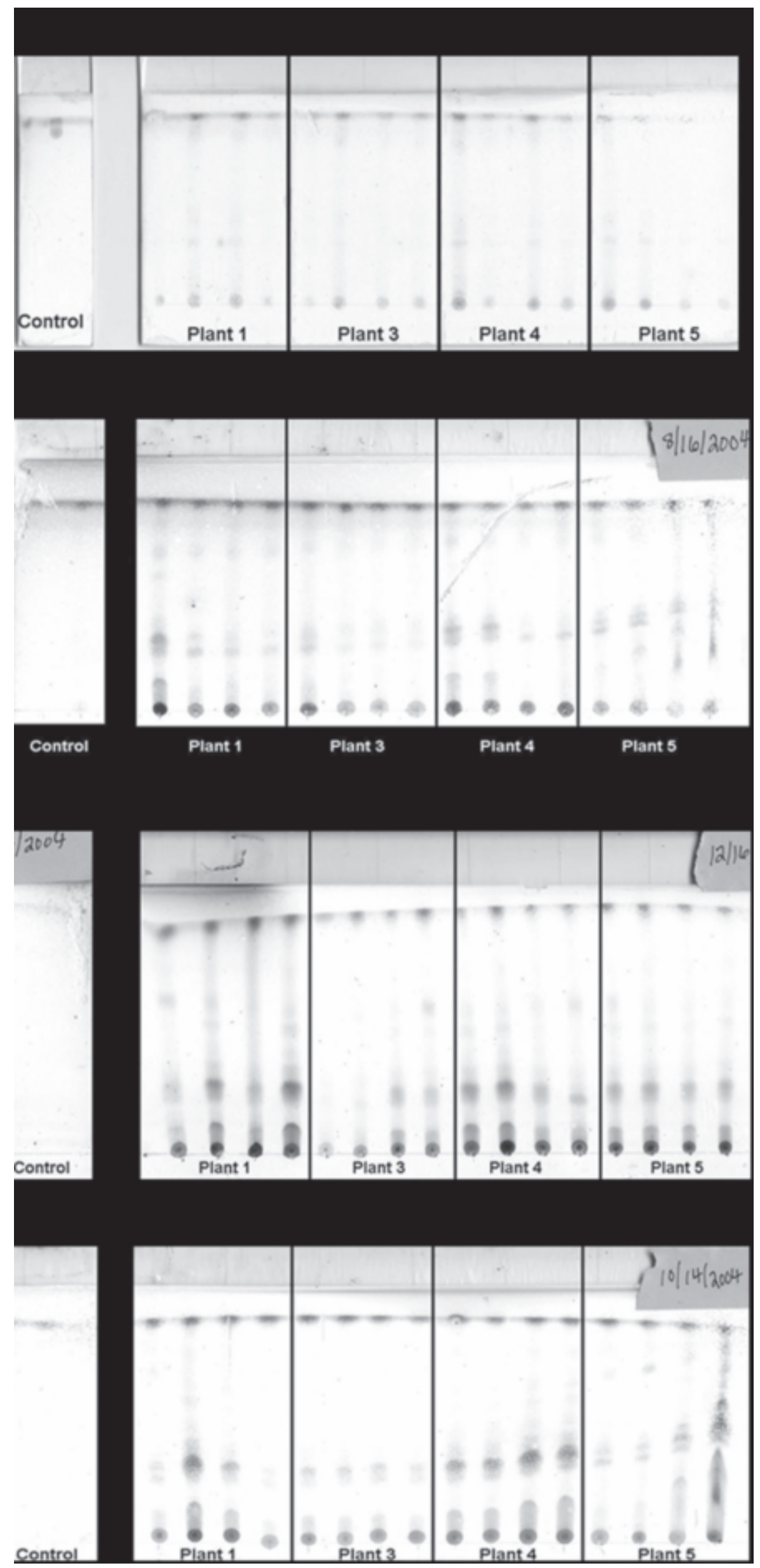




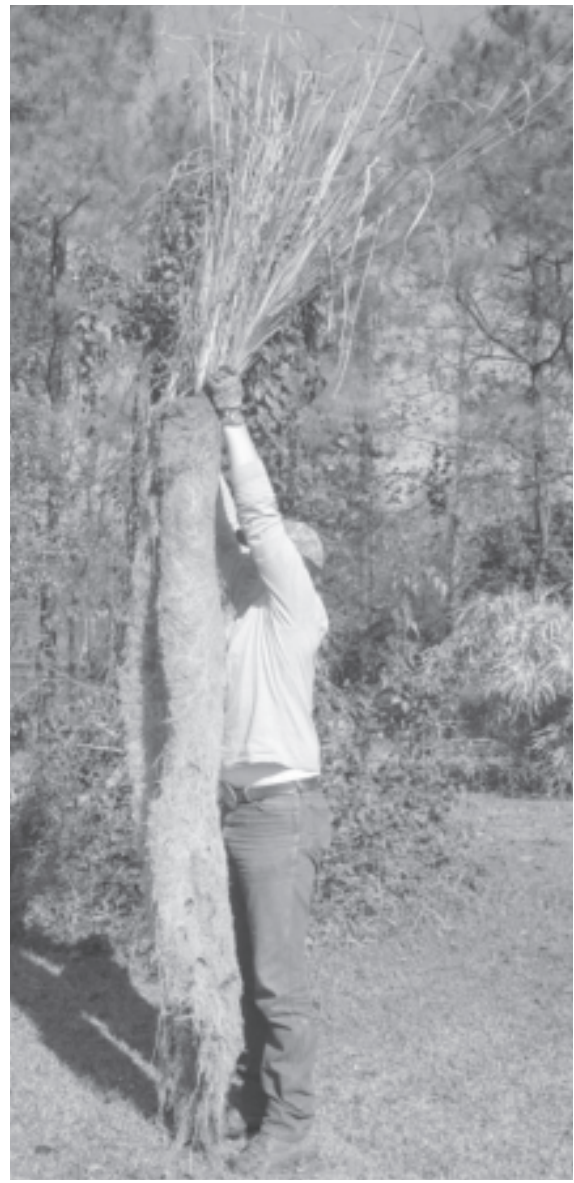

Fig. 3. Total root growth of vetiver grass 8 months after planting. The person holding the vetiver grass plant is $1.97 \mathrm{~m}$ tall.

The roots extracted from the PVC pipe at the end of the experiment were approximately $25 \mathrm{~cm}$ in diameter; over $2 \mathrm{~m}$ long (Fig. 3), and weighed $0.48 \mathrm{~kg}$. Roots were also present below ground level, but we were unable to determine how far they extended.

Vetiver grass root as mulch against termites. The total length of tunnels by Formosan subterranean termites in $5 \%, 10 \%$, and $25 \%$ treatments was not significantly different from the control at day 4 and day $8(P>0.05)$ (Table $3)$. On days 12 and 16, tunneling length was significantly less only in the $25 \%$ vetiver root mulch treatments when compared to the controls ( $P=0.04$ or 0.03 , respectively) (Table 3 ). In two replications of 5\% vetiver root mulch, four replications of $10 \%$ vetiver root mulch, and

Table 4. Mean percentage of termite mortality \pm SD and wood consumption \pm SD obtained after $16 \mathrm{~d}$.

\begin{tabular}{lcc}
\hline & $\begin{array}{c}\text { Mean } \\
\text { mortality } \\
(\%)\end{array}$ & $\begin{array}{c}\text { Mean } \\
\text { wood } \\
\text { consumption } \\
(\%)\end{array}$ \\
Treatment & $4.8 \pm 3.8 \mathrm{a}^{2}$ & $47.4 \pm 32.2 \mathrm{a}$ \\
Control & $43.4 \pm 30.8 \mathrm{ab}$ & $17.0 \pm 15.7 \mathrm{ab}$ \\
$5 \%$ & $72.4 \pm 21.8 \mathrm{~b}$ & $2.6 \pm 5.2 \mathrm{~b}$ \\
$10 \%$ & $58.4 \pm 25.7 \mathrm{~b}$ & $0.9 \pm 0.6 \mathrm{~b}$ \\
$25 \%$ &
\end{tabular}

${ }^{2}$ Means followed by the same letter within a column are not significantly different at 0.05 level as determined by Tukey's studentized range (HSD) test.
Table 3. Mean total length $\pm \mathrm{SD}(\mathrm{cm})$ of tunnels for all observation days for each treatment of vetiver grass root mulch.

\begin{tabular}{lcccc}
\hline Treatment & Day 4 & Day 8 & Day 12 & Day 16 \\
\hline Control & $34.1 \pm 22.6 \mathrm{a}^{\mathrm{z}}$ & $30.9 \pm 12.1 \mathrm{a}$ & $43.8 \pm 4.94 \mathrm{a}$ & $43.9 \pm 5.2 \mathrm{a}$ \\
$5 \%$ & $31.3 \pm 12.7 \mathrm{a}$ & $26.6 \pm 10.8 \mathrm{a}$ & $32.0 \pm 15.1 \mathrm{ab}$ & $34.4 \pm 12.4 \mathrm{ab}$ \\
$10 \%$ & $28.9 \pm 4.1 \mathrm{a}$ & $26.6 \pm 2.1 \mathrm{a}$ & $31.0 \pm 8.2 \mathrm{ab}$ & $29.9 \pm 11.3 \mathrm{ab}$ \\
$25 \%$ & $18.9 \pm 6.7 \mathrm{a}$ & $23.0 \pm 9.3 \mathrm{a}$ & $23.5 \pm 8.5 \mathrm{~b}$ & $24.8 \pm 6.2 \mathrm{~b}$ \\
\hline
\end{tabular}

${ }^{\mathrm{z}}$ Means followed by the same letter within a column are not significantly different at 0.05 level as determined by Tukey's studentized range (HSD) test. all five replications of $25 \%$ vetiver root mulch, termites did not tunnel all the way through the treatment chamber to get to the food chamber. Instead of displaying the normal exploratory behavior, on days 8,12 , and 16 , termites in the nest and treatment chambers of all vetiver root mulch treatments were very sluggish and remained clumped together. Consumption of wood was significantly lower in vetiver root mulch treatments of $10 \%$ and $25 \%(P=0.001)$ (Table 4). The highest wood consumption was recorded in control and 5\% vetiver root mulch treatments, which were not significantly different from each other. Termites in treatments consisting of $10 \%$ and $25 \%$ vetiver root mulch exhibited significantly higher mortality rates $(P=0.002)$ than termites present in controls (Table 4).

\section{Discussion}

In the field study, as mean root weight increased there was an increase in the amount of vetiver oil present in the roots. It is also important to note that as vetiver plants age, the amount of vetiver oil in the root system also increases (Chomchalow, 2001).

Root growth of a plant can be affected by daily temperatures, moisture, and/or texture of the soil in which it is planted (Wang, 2001). Vetiver grass is a tropical plant species able to withstand extreme heat, and is usually unable to survive in subfreezing temperatures (National Research Council, 1993). The dramatic increase in root growth observed during the final sampling date can be attributed to the daily temperatures and/or soil temperatures at that time of the year. The third and fourth sampling dates took place in mid-October and mid-December, respectively. During this time period, the average daily temperature was 18 ${ }^{\circ} \mathrm{C}$ (http://www.agctr.lsu.edu/weather/) (Table $5)$. This temperature coincides with results reported by Wang (2001), where longest root growth occurred in plants subjected to temperature treatments of $25 / 20^{\circ} \mathrm{C}$. Soil temperatures in these treatments also provided for the fastest rate of root growth $\left(4 \mathrm{~cm} \cdot \mathrm{d}^{-1}\right)$ (Wang, 2001). Soil temperatures reported at Louisiana State
University Agricultural Center's St. Gabriel Research Station (http://www.agctr.lsu.edu/ weather/), St. Gabriel, (about 2 miles from the site of this study), averaged $20^{\circ} \mathrm{C}$ for the time when root growth was greatest (Table 5).

While vetiver plants are still mainly grown increasing popular due to the increased use of vetiver oil in aromatherapy; resulting in a supply shortage from producing countries (Chomchalow, 2003). In Thailand, in an effort to increase the amount of roots harvested, vetiver plants have been planted in-ground in large sand-filled polyethylene bags (Chomchalow, 2000). After 1 year, this method yielded about $0.5 \mathrm{~kg}$ of roots per plant. The method of growing vetiver plants described in the present field study allows for an effortless harvest of the maximum yield of root mass. Because of the increasing popularity of vetiver grass roots and its multitude of uses, this method of growing and harvesting vetiver grass may be advantageous to many horticultural enterprises.

Mulches are materials spread over soil surfaces to reduce moisture evaporation, protect soil from erosion, to provide insulation during periods of extreme temperatures, and to inhibit weed growth (Long et al., 2001). Organic mulches such as leaves, pine bark, pine needles, or wood chips are the most widely used (Gill, 2005a; Long et al., 2001) and because these mulches are mainly comprised of cellulose, they are at risk for attack by termites. Also, because mulches protect the soil by conserving moisture, they create a hospitable environment for termites (Gill, 2005b). While data indicate that organic mulches do not increase the rate of termites scouting to the area (Long et al., 2001), because mulches are often placed directly against a home's foundation, they can provide a hidden, direct entryway for termites into a home. In cases where mulches are placed atop soils previously treated with termiticides, mulches provide a bridge allowing termites to cross over treated soil (Forschler, 1998; Long et al., 2001). Because vetiver oil has been shown to be repellent and toxic to termites, it has been of great interest to homeowners aware of the discovery to know if vetiver grass planted for soil and water conservation, it is becoming

Table 5. Average daily and soil temperatures between sampling dates reported at Louisiana State University Agricultural Center's St. Gabriel Research Station.

\begin{tabular}{lccc}
\hline & $\begin{array}{c}\text { Avg } \\
\text { daily } \\
\text { temp } \\
\left({ }^{\circ} \mathrm{C}\right)\end{array}$ & $\begin{array}{c}\text { Avg } \\
\text { soil } \\
\text { temp } \\
\text { Date }\end{array}$ & $\begin{array}{c}\text { Increase in } \\
\text { root growth from } \\
\text { previous sampling } \\
\text { date }(\%)\end{array}$ \\
\hline 16 Apr-16 June & 23 & 27 & N/A $^{z}$ \\
17 June-6 Aug. & 27 & 31 & 0 \\
17 Aug.-14 Oct. & 26 & 29 & 113 \\
15 Oct.-16 Dec. & 18 & 20 & 520 \\
\hline
\end{tabular}

${ }^{\mathrm{z}}$ Since the study began on $16 \mathrm{Apr}$, no previous data existed on root growth for the 16 June collection. 
around the perimeter of a structure or vetiver grass roots as mulch would provide a zone of repellency against this structural pest. Results of the $25 \%$ vetiver root mulch treatments are similar to results of previous evaluations of decreased tunneling, decreased food consumption, and increased mortality of termites (with and without direct contact to treatments) in wood or sand treated with vetiver oil or its constituents (Ibrahim et al., 2004; Maistrello et al., 2000, 2001, 2002; Nix et al., 2003; Zhu et al., 2001a, 2001b).

In four replications of the $10 \%$ vetiver root mulch and all five replications of the 25\% vetiver root mulch treatments, no consumption was present on the untreated pieces of wood present in the food chamber. While the mean percent wood consumption in the $25 \%$ vetiver root mulch treatment indicated a slight amount of consumption, the difference was due to the fluctuation in relative humidity. A previous wood treatment study indicated that wood treated with vetiver oil or nootkatone was not only toxic but acted as feeding deterrents and arrestants (Maistrello et al., 2001). The unusual behavior exhibited by termites in the presence of vetiver root mulch observed on days 8,12 , and 16 , is described as lingering behavior (Maistrello et al., 2002). In our laboratory evaluation, the highest tested vetiver root mulch to sand ratio proved to decrease tunneling activity and wood consumption and increase termite mortality. These results provide evidence that vetiver grass roots may be useful as a repellent to termites in urban landscapes.

\section{Literature Cited}

Cazuassus,A.,P.Y.Roze, andN. Sellier. 1989. Positive and negative chemical ionization $\mathrm{GC} / \mathrm{MS}$ and GC/ MS/MS for chromatographic studies of vetiveryl acetate. Use of MS/MS for the differentiation of isomeric sesquiterpenes. Chromatographia 28:579-584.

Chomchalow, N.2000. Techniques of vetiver propagation with special reference to Thailand. Technical Bulletin No. 2000/1,Pacific Rim Vetiver Network /Office of the Royal Development Projects Board,
Bangkok, Thailand.

Chomchalow, N. 2001. The utilization of vetiver as medicinal and aromatic plants with special reference to Thailand. Pacific Rim Vetiver Network /Office of the Royal Development Projects Board (Bangkok, Thailand) Tech. Bul. 2001/1.

Chomchalow, N. 2003. Other uses and utilization of vetiver, p. 474-485. Proceedings of the 3rd Conference of Vetiver and Exhibition, 6-9 Oct. Guangzhou, China.

Duke, S.O. 1990. Natural pesticides from plants, p. 511-517. J. Janick and J. E. Simon (eds.) Advances in new crops. Timber Press, Portland, Ore.

Forschler, B.T. 1998. Subterranean termite biology in relation to prevention and removal of structural infestation. NPCA (Dunn Loring, Va.) Res. Rpt. on Subterranean Termites.

Forschler, B.T. and T.M. Jenkins. 2000. Subterranean termites in the urban landscape: Understanding their social structure is the key to successfully implementing population management using bait technology. Urban Ecosystems 4:231-251.

Gill, D. 2005a. Mulching makes gardening easy. 25 Aug. 2005. http://www.lsuagcenter.com/ en/communications/news/get_it_growing/ Weekly+Columns/Mulching+Makes + Gardenin $\mathrm{g}+$ Easier.htm.

Gill, D. 2005b. Integrated pest management of termites in the landscape. 25 Aug. 2005. http:// www.lsuagcenter.com/en/family home/home/ pest_management/integrated + pest + managemen $\mathrm{t}+\mathrm{of}+$ termites $+\mathrm{in}+\mathrm{the}+$ landscape.htm.

Gold, R.E., H.N. Howell Jr., G.J. Glenn. 1999. Formosan subterranean termites. Texas A\&M Univ. Agr. Ext. Serv. 25 Aug. 2005. http://www.spcbtx. org/consumer/formosan.pdf.

Greenfield, J. 2002. Vetiver grass - An essential grass for the conservation of planet Earth. Infinity Publ. http://www.vetiver.org/TVN book.pdf.

Henderson, G., R.A. Laine, D.O. Heumann, F. Chen, and B.C.R. Zhu. 2005a. Extracts of vetiver oil as repellents and toxicants to ants, ticks, and cockroaches. U.S. Patent No. 6,906,108 B2.

Henderson, G., R.A. Laine, D.O. Heumann, F. Chen, and B.C.R. Zhu. 2005b. Vetiver oil extracts as termite repellent and toxicant. U.S. Patent $6,890,960 \mathrm{~B} 1$.

Ibrahim, S.A., G. Henderson, and R.A. Laine. 2004. Toxicity and behavioral effects of nootkatone, 1, 10-dihydronootkatone and tetrahydronootkatone on the Formosan subterranean termite (Isoptera: Rhinotermitidae). J. Econ. Entomol
97(1):102-111.

Long C.E., B.L. Thorne, N.L. Breisch, and L.W. Douglas. 2001. Effect of organic and inorganic landscape mulches on subterranean termite(Isoptera: Rhinotermitidae) foraging activity. Environ. Entomol. 30(5):832-836.

Maistrello, L., G. Henderson, and R.A. Laine. 2000. Effects of nootkatone and a borate compound on Formosan subterranean termite (Isoptera: Rhinotermitidae) and its symbiotic protozoa. J. Entomol. Sci. 36:229-236.

Maistrello, L., G. Henderson, and R.A. Laine. 2001. Efficacy of vetiver oil and nootkatone as soil barriers against Formosan subterranean termite (Isoptera: Rhinotermitidae). J. Econ. Entomol. 94:1532-1537.

Maistrello, L. G. Henderson, and R.A. Laine. 2002. Comparative effects of vetiver oil, nootkatone, and disodium octoborate tetrahydrate on Coptotermes formosanus and its symbiotic fauna. Pest Mgt. Sci. 59:58-68.

Mao, L., G. Henderson, and R.A. Laine. 2004. Germination of various weed species in response to vetiver oil and nootkatone. Weed Technol. 18:263-267.

National Research Council. 1993. Vetivergrass:Athin line against erosion. In: N.D. Veitmeyer and F.R. Ruskin (eds.). Board on Science and Technology for International Development. NationalAcademy Press, Wash., D.C.

Nix, K.E., G. Henderson, and R.A. Laine. 2003. Field evaluation of nootkatone and tetrahydronootkatone against Coptotermes formosanus. Sociobiology 42(2)413-424.

SAS Institute. 1989. SAS/STAT user's guide. SAS Inst., Cary, N.C.

Statsoft, Inc. 2004. Statistica 7. Statsoft, Inc., Tulsa, Okla.

Wang, Y.W. 2001. The root extension rate of vetiver under different temperature treatments. Proceedings of the Second International Conference on Vetiver. Office of the Royal Development Projects Board, Bangkok, Thailand. http://www.vetiver. org/TAI temp.pdf.

Zhu, B., G. Henderson, F. Chen, L. Maistrello, and R. A. Laine. 2001a. Nootkatone is a repellent for Formosan subterranean termites (Coptotermes formosanus). J. Chem. Ecol. 27(3):523-531.

Zhu, B., G. Henderson, F. Chen, H. Fei, and R.A. Laine. 2001b. Evaluation of vetiver oil and seven insect-active essential oils against the Formosan subterranean termite. J. Chem. Ecol. 27(8):1617-1625 